\title{
A Semianalytical Model for Analyzing the Infill Well-Caused Fracture Interference from Shale Gas Reservoirs
}

\author{
Sidong Fang, ${ }^{1,2}$ Yonghui Wu $\mathbb{D}^{3},{ }^{3}$ Cheng Dai, ${ }^{1,2}$ Liqiang Ma $\mathbb{D}^{3}$ and Hua Liu ${ }^{1,2}$ \\ ${ }^{1}$ State Key Laboratory of Shale Oil and Gas Enrichment Mechanisms and Effective Development, Beijing, China \\ ${ }^{2}$ Sinopec Key Laboratory of Shale Oil/Gas Exploration and Production Technology, Beijing, China \\ ${ }^{3}$ Key Laboratory of Deep Coal Resource Mining (China University of Mining \& Technology), Ministry of Education, China
}

Correspondence should be addressed to Yonghui Wu; wuyonghuijr@cumt.edu.cn

Received 13 September 2021; Accepted 19 October 2021; Published 1 November 2021

Academic Editor: Xiang Zhou

Copyright (C) 2021 Sidong Fang et al. This is an open access article distributed under the Creative Commons Attribution License, which permits unrestricted use, distribution, and reproduction in any medium, provided the original work is properly cited.

Drilling infill well has been widely used in many plays to enhance the recovery of shale gas, but the infill well-caused fracture interference is a very important issue that should be taken into consideration. The well interference makes it difficult for the conventional models to make production predictions, fracture characterization, and production data analysis. In this paper, a semianalytical model is proposed for this purpose by discretizing the whole control volume of the parent and infill wells into several linear flow zones. In this way, three important issues can be further handled very naturally, including fracture connection between the parent and infill wells, different SRV properties for zones with different distances to the wellbore, and different production times for adjacent wellbores. The approximate expressions for different flow regimes are used in making production predictions in the time domain, and a flowing material balance method and a simple iteration are used to update the model parameters step by step. The proposed model is shown to be reasonable and accurate for handling multiwell interference problems after comparing with the commercial numerical simulator tNavigator. The synthetical cases show that the fracture parameters, SRV properties, and well infill time have a significant influence on the production performance of both the parent and infill wells. The results show that the production of the parent well will be dramatically enhanced when it is connected with the infill well via high-conductive hydraulic fractures. Longer unconnected fractures and more fracturing stages/clusters for the infill well will result in higher production for the infill well, but a negative effect is observed for the parent well. The permeability of the distant well SRV has a similar influence on the parent and infill wells. The results also show that late time well interference will result in a more significant increase in production rate on the log-log plots for the severe depletion around the parent well. Finally, the proposed model is used to analyze the production data of a field case from Fuling shale in Southwestern China. After analyzing the production data, several parameters can be obtained for both parent and infill wells, including the fracture lengths and conductivities, numbers of connected fractures, and the near and distant well permeabilities of the SRV. This gives a basic and practical technique for production prediction, formation and fracture evaluation, and well connectivity analysis from shale gas wells with fracture connection.

\section{Introduction}

With the development of the technology in drilling long horizontal wells and multiple-stage hydraulic fracturing, unconventional shale gas resources have been economically developed in many counties around the world, such as the USA, China, and Canada [1]. However, the recovery of shale gas is quite low at present because of the high decline rate in shale gas production. At present, several techniques are presented for this problem, including $\mathrm{CO}_{2}$ sequestration in the shale formation [2-4] and refracturing and drilling infill wells $[5,6]$. In particular, drilling infill wells are widely used in many plays and the well spaces have been tightened to 200 300 meters. A major concern of drilling an infill well is the infill well-caused well interference, which makes it difficult for making production predictions and interpreting the fracture parameter and evaluating the well connectivity. 
Many researchers have reported the well interference phenomenon from several aspects, including fracture prorogation simulation, field microseismic monitoring, and production and pressure tests. Fracture prorogation studies show that fractures growing from adjacent wells tend to attract each other and result in fracture connections [7]. Field microseismic data also show that the phenomenon of fracture connection between adjacent wells is quite common, especially for infill well cases, where there is pressure sink in the formation after the long-time production $[8,9]$. Production and pressure tests show that the pressure, and gas, and water production of a parent well will dramatically change after the hydraulic fracturing of an adjacent infill well [10-12]. Therefore, it is of great importance to analyze the effects of infill well-caused fracture interference for shale gas reservoirs.

Numerical models are quite comprehensive and robust for fracture interference analysis for their ability in handling complex fracture networks, nonlinearities, heterogeneities, and other complex problems. The present numerical models mainly include discrete fracture models (DFM) and embedded discrete fracture models (EDFM) [13-19]. The EDFM is quite efficient in analyzing the effects of infill well-caused fracture interference because the time-consuming grid system is not needed to be discretized two times after adding the infill well. Green element method- (GEM-) based discrete fracture model is another efficient method for unconventional reservoir simulation, which borrows the advantages of EDFM in discretization and the boundary element method (BEM) in precision $[20,21]$. By using numerical models, several studies have studied the effects of well interference on the production and pressure performance [22-25]. In these studies, the wells are assumed to be connected with low-conductivity reactivated natural fractures and high-conductivity hydraulic fractures.

Because numerical models are often time-consuming in matching the production and pressure data when there are many fractures in the model, analytical models are still often used in reservoir engineering. The analytical models for unconventional oil and gas reservoirs are often based on linear flow assumptions for the long-time linear flow regimes observed in the field. In the linear flow models, the reactivated natural fractures are treated using the SRV concept and the analytical solutions can be derived by discretizing the whole control volume of the wellbore with several linear flow zones [26-28]. Several studies also enriched the analytical models to more complex problems, such as the twophase flow in retrograde gas and condensate oil reservoirs, and early-time two-phase flow back data analysis [29, 30]. Some studies also use this concept to approximately analyze the production data for wells with fracture interference [12, 31-33]. The slopes exhibited by the pressure and rate curves on the log-log plots are used to diagnose the well interference. It is reported that well interference will increase the decline rate on the type curves. However, the present analytical model can only be used for production decline analysis qualitatively. In addition, the wells are assumed to start producing at the same time, so the problem of infill well-caused fracture interference is not considered in these models.
In this paper, we will present a semianalytical model for production prediction and production data analysis based on the linear flow assumptions. This model mainly handled three important problems concerning the well interference, including different production times for different wells, well connections with part of the fractures, and different formation properties for near and distant well SRV regions. In the following, we first presented the mathematical fundamentals of the semianalytical model. Then, the proposed model is benchmarked with a commercial simulator and several synthetical cases are used to analyze the effects of different parameters. Finally, a field case is used to show the application of the proposed model.

\section{Methodology}

2.1. Physical Model. For shale gas reservoirs, as shown in Figure 1, multiple high-conductive fractures and an SRV will be generated after hydraulic fracturing. Before adding the infill well and there is no well interference, the SRV is near the parent well, just like $S R V_{1}$ in Figure 1(a) and $S R V_{1}$ and $\mathrm{SRV}_{5}$ in Figure 1(b). After the hydraulic fracturing of the infill well, SRV can be generated near the infill well, just like $\mathrm{SRV}_{3}$ in Figure 1 (a) and $\mathrm{SRV}_{3}$ in Figure 1(b). In addition, the distant well area can also be stimulated because the depletion around the parent well and the hydraulic fractures are tending to propagate into the SRV of the parent well. Therefore, some fractures will be connected between the parent and infill wells and the distant well SRV can be generated, just like $\mathrm{SRV}_{2}$ in Figure 1(a) and $\mathrm{SRV}_{2}$ and $\mathrm{SRV}_{4}$ in Figure 1(b).

In this paper, we assume that part of the distant well SRV will contribute to the parent well and the other part will contribute to the infill well. The distant well SRV, including SRV2 in Figure 1(a) and SRV2 and SRV4 in Figure 1(b), contribute to both the parent and infill wells, so there should be a contribution ratio to the parent well, which can be defined using the fracture length. Based on this assumption, the representative zones can be obtained in Figure 1 for both parent and infill wells. For the two-well case shown in Figure 1(a), zones A and B are the representative zones of the parent well and the whole control volume of the parent well can be formed with the combinations of A and B. For the infill well shown in Figure 1(a), zones $C$ and $D$ can be regarded as the representative zones. One should note that zones $\mathrm{A}$ and $\mathrm{C}$ are different models because the near and distant well SRVs are not stating produce at the same time. In the same way, we can analyze the three-well case shown in Figure 1(b). Another assumption is that the unstimulated reservoir volume is not considered in this model because the production contribution from the unstimulated reservoir is not significant. In addition, this contribution cannot be observed on log-log plots in late flow regimes.

Taking half of the representative zones shown in Figure 1, as shown in Figure 2, we can further extract the basic linear flow models, including the two-region linear flow model, convergence linear flow model, and singlelinear flow model. In this way, we can simplify the complex multiwell interference model to basic linear flow models. In 


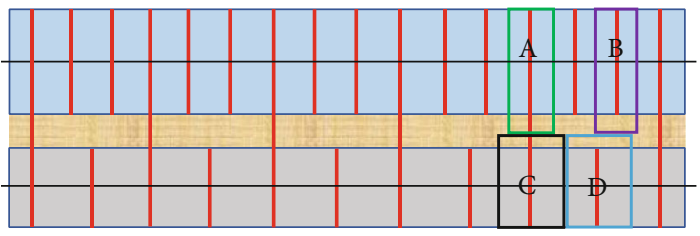

(a) Two-well interference

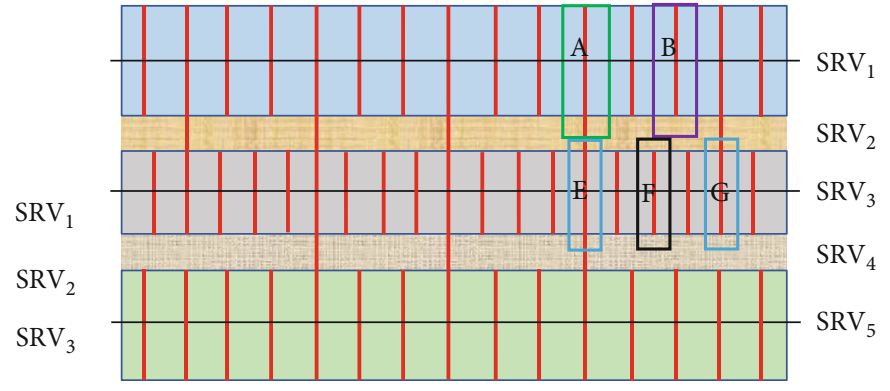

(b) Three-well interference

Figure 1: Schematic of a well pad with fracture connection between the parent and infill wells.

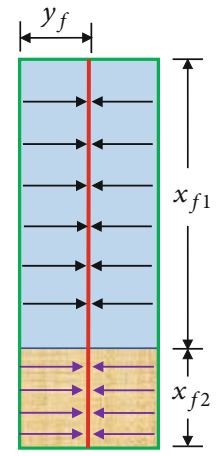

(a) Two-region linear

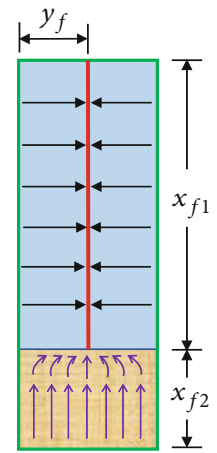

(b) Convergence linear

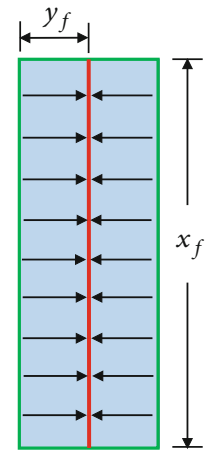

(c) Single linear

FIGURE 2: Schematic of the typical flow models for analyzing the infill well-caused fracture interference.

Section 2.2, we will present the mathematical fundamentals for the physical model.

\subsection{Mathematical Model}

2.2.1. Analytical Solution in Linear Systems. For the singlelinear flow, taking the schematic shown in Figure 2(c) for example, the governing equation can be given by

$$
\frac{\partial^{2} \psi_{D}}{\partial y_{D}^{2}}=\frac{1}{\eta_{D}} \frac{\partial \psi_{D}}{\partial t_{D}}
$$

It should be noted that the gas desorption from the tight matrix pores is considered using desorption compressibility, which is defined by $c_{d}=\left(\left(p_{\mathrm{sc}} Z T\right) /\left(\phi Z_{\mathrm{sc}} T_{\mathrm{sc}}\right)\right)\left(\left(V_{L} p_{L}\right) /(p\right.$ $\left.\left.\left(p_{L}+p\right)^{2}\right)\right)$ in our previous work [34]. Here, we should state that the geomechanics and complex transport mechanisms in the shale nanopores are not seriously considered in this analytical model [35-42]. In this model, these transport mechanisms can be characterized using apparent permeability and handled with the pseudopressure approximately in the analytical model. The pseudopressure can be defined with $\psi=2 \int_{0}^{p}\left(\left(f_{\text {app }} p\right) /(\mu Z)\right) d p$, where $f_{\text {app }}$ is a permeability modifier.

The definitions of the dimensionless variables are shown in Table 1.
The initial condition is given by

$$
\left.\psi_{D}\right|_{t_{D}=0}=0 .
$$

The inner boundary condition is

$$
\left.\frac{\partial \psi_{D}}{\partial y_{D}}\right|_{y_{D}=y_{f D}}=0 .
$$

The outer boundary condition is coupled with the hydraulic fractures. Since infinite-conductivity fracture is assumed in this model, the inner boundary condition can be written as

$$
\left.\psi_{D}\right|_{y_{D}=0}=1+s_{c} .
$$

Laplace transformation can be used to obtain the analytical solution of the single-linear flow model shown in equations (1)-(3). According to our previous work [43], the production solution can be directly given by

$$
\bar{q}_{D}=\frac{1+s_{c}}{s} \frac{k_{D} x_{f D}}{\pi} \sqrt{\frac{s}{\eta_{D}}} \tan h\left(\sqrt{\frac{s}{\eta_{D}}} \cdot y_{f D}\right) .
$$

It should be noted that the numerical algorithm proposed by Stehfest should be used to obtain the solution of equation (5) in the time domain [44]. Because there are mainly two flow regimes for the infinite conductive fracture 
TABLe 1: Definitions of the dimensionless parameters used in the model derivation.

\begin{tabular}{|c|c|c|c|}
\hline Variables & Definition & Variables & Definition \\
\hline $\begin{array}{l}\text { Dimensionless pressure for gas } \\
\text { (at constant rate) }\end{array}$ & $\psi_{D}=\left(k_{r} H\left(\psi_{i}-\psi\right)\right) /\left(1.291 \times 10^{-3} q_{\mathrm{sc}} T\right)$ & $\begin{array}{l}\text { Dimensionless pressure for gas } \\
\text { (at constant BHP) }\end{array}$ & $\psi_{D}=\left(\psi_{i}-\psi\right) /\left(\psi_{i}-\psi_{\mathrm{wf}}\right)$ \\
\hline $\begin{array}{l}\text { Dimensionless rate for oil } \\
\text { (at constant rate) }\end{array}$ & $\psi_{D}=\left(k_{r} H\left(p_{i}-p\right)\right) /\left(1.842 q_{\mathrm{sc}} B \mu\right)$ & $\begin{array}{l}\text { Dimensionless pressure for oil } \\
\text { (at constant BHP) }\end{array}$ & $\psi_{D}=\left(p_{i}-p\right) /\left(p_{i}-p_{\mathrm{wf}}\right)$ \\
\hline Reference diffusivity $\left(10^{6} \mathrm{mD} / \mathrm{s}\right)$ & $\eta_{r}=0.0864 k_{r} /\left(\phi c_{t} \mu\right)_{r}$ & Dimensionless time & $t_{D}=\left(\eta_{r} / L_{r}^{2}\right) t$ \\
\hline Dimensionless length: $x$ direction & $x_{D}=x / L_{r}$ & Dimensionless length: $y$ direction & $y_{D}=y / L_{r}$ \\
\hline Dimensionless diffusivity & $\eta_{D}=\left(\eta / \eta_{r}\right)=\left(1 / \eta_{r}\right)\left(0.0864 k / \phi c_{t} \mu\right)$ & Dimensionless permeability & $k_{D}=k / k_{r}$ \\
\hline
\end{tabular}

model, linear flow regime, and boundary dominated flow regime, the regional approximate solutions [45] can be used to simplify the solution.

For the linear flow regime, the solution for the constant bottom hole pressure condition case is given by

$$
\frac{1}{q_{D}}=\frac{1}{1+s_{c}} \frac{\pi}{2 k_{D} x_{f D}} \sqrt{\pi \eta_{D} t_{D}} .
$$

Taking the dimensionless variables into equation (6), we can obtain

$$
q_{\mathrm{sc}}=\frac{2}{\pi} \frac{\left(1+s_{c}\right) k H\left(\psi_{i}-\psi_{\mathrm{wf}}\right) x_{f}}{1.291 \times 10^{-3} T \sqrt{\pi \bar{\eta} t}} .
$$

For the long-term boundary-dominated flow regime, the solution can be written as

$$
q_{\mathrm{sc}}=\alpha_{g} \frac{\pi}{2} \frac{k H\left(\bar{\psi}-\psi_{\mathrm{wf}}\right)}{1.291 \times 10^{-3} T} \frac{x_{f}}{y_{f}} .
$$

$\alpha_{g}$ is a factor, which makes the production rate curves continuous at the connection of the two flow regimes. The value of $\alpha_{g}$ can be determined using the following expression

$$
\left.q_{s c}\right|_{\text {linear flow, } t_{\text {elf }}}=\left.q_{s c}\right|_{\text {boundary dominated flow, } t_{\text {elf }}},
$$

where $t_{\text {elf }}$ is the time of deviation from the linear flow regime to the boundary-dominated flow regime and it can be estimated as follows:

$$
t_{\mathrm{elf}}=\frac{\phi \mu_{i} \mathrm{c}_{t i}}{k}\left(\frac{y_{f}}{0.5836}\right)^{2}
$$

The bilinear flow may occur when the permeability of the SRV is high and the fracture cannot be regarded as infinitely conductive. In this case, the approximation of the production [43] can be given as

$$
\frac{1}{q_{D}}=\frac{1}{1+s_{c}} \frac{1.2254 \pi}{\sqrt{k_{D} k_{f D} w_{f D}}} \sqrt[4]{\eta_{D} t_{D}}
$$

Taking the dimensionless variables into equation (11), we can obtain

$$
q_{\mathrm{sc}}=201.4 \sqrt{k k_{f} w_{f}} \frac{\left(1+s_{c}\right) H\left(\psi_{i}-\psi_{\mathrm{wf}}\right)}{T \sqrt[4]{\bar{\eta} t}} .
$$

2.2.2. Average Pressure Calculation. We can find that some parameters in equations (7) and (8) are average pressure dependent, such as $\bar{\eta}_{j}$ and $\bar{\psi}$. Therefore, to obtain the production solution of the system, another step is to obtain the average pressure. In this section, the flowing material balance equations are used for this purpose. According to equation (10), the distance of investigation can be written as

$$
y_{\mathrm{inv}}=0.5836 \sqrt{\frac{k t}{\phi \mu_{i} c_{t i}}} .
$$

Therefore, for the single-linear flow system, the control volume of the fracture can be given by

$$
V_{\mathrm{inv}}=4 x_{f} y_{\mathrm{inv}} H \phi
$$

Using the material balance method, we can obtain

$$
G_{p}=\text { IGIP }- \text { RGIP } .
$$

In which, $G_{p}$ is the cumulative gas production, IGIP is the initial gas reserve, RGIP is the remaining gas reserve, and they can be calculated with

$$
G_{p}=\int_{0}^{t} q_{g s c} d t
$$

$$
\begin{gathered}
\mathrm{IGIP}=V_{\text {inv }}\left(\frac{S_{g i}}{B_{g i}}+\frac{V_{\mathrm{L}} p_{\mathrm{i}}}{p_{\mathrm{L}}+p_{\mathrm{i}}}\right), \\
\mathrm{RGIP}=V_{\text {inv }}\left(\frac{S_{g i}}{\bar{B}_{g}}+\frac{V_{L} \bar{p}}{p_{L}+\bar{p}}\right) .
\end{gathered}
$$

It should be noted that the water in the formation is irreducible, so the initial gas saturation is used in equation (18). 

obtain

Taking equations (16)-(18) into equation (15), we can

$$
\frac{S_{g i}}{\bar{B}_{g}}+\frac{V_{L} \bar{p}}{p_{L}+\bar{p}}=\frac{S_{g i}}{B_{g i}}+\frac{V_{L} p_{i}}{p_{L}+p_{i}}-\frac{G_{p}}{V_{\mathrm{inv}}} .
$$

Equation (19) can be rewritten as

$$
f(\bar{p})=\frac{S_{g i}}{\bar{B}_{g}}+\frac{V_{L} \bar{p}}{p_{L}+\bar{p}}+\frac{G_{p}}{V_{\mathrm{inv}}}-\frac{S_{g i}}{B_{g i}}-\frac{V_{L} p_{i}}{p_{L}+p_{i}}=0 .
$$

Taking the derivation of Eq. (20), we obtain

$$
f^{\prime}(\bar{p})=-\frac{S_{g i}}{\bar{B}_{g}^{2}} \frac{d B_{g}}{d p}+\frac{V_{\mathrm{L}} p_{\mathrm{L}}}{\left(p_{\mathrm{L}}+\bar{p}\right)^{2}} .
$$

We can use the Newton-Raphson iteration to solve equations (20) and (21). The iteration equation can be written as

$$
\bar{p}_{k+1}=\bar{p}_{k}-\omega \frac{f\left(\bar{p}_{k}\right)}{f^{\prime}\left(\bar{p}_{k}\right)},
$$

where $\omega$ depends on the iteration steps $n, \omega=1 / 2^{n-1}$.

2.2.3. Production Prediction for Different Regions. For the cases shown in Figure 1, the whole reservoir can be characterized with representative regions, including A-G. In addition, each region is combined with the typical flow models shown in Figure 2.

For the model shown in Figure 1(c), the solution can be obtained using the mathematical derivations shown in Sections 2.3.1 and 2.3.2. The detailed procedure can be concluded in Figure 3.

Using the procedure for a single-linear flow, we can obtain the production of the typical regions and the horizontal wells. Table 2 shows the composition of different regions shown in Figure 1. For the parent and infill wells, the total gas production is the summation of different typical regions. It should be noted that the production times for the parent and infill wells are different, so this should be considered in predicting the production of the parent wells.

\section{Results and Discussion}

In this section, we will first validate the proposed semianalytical model by using the commercial numerical simulator tNavigator. Then, we will analyze the effects of the connection condition between the parent and infill wells on the production performance. Finally, a field case from the Fuling shale gas field in Southwestern China is provided to show the application of the proposed model. Because only a twowell interference field case is accessible at present, the case shown in Figure 1(a) is analyzed in this section. However, the same method can be used for cases shown in Figure 1(b).

3.1. Model Validation. In this section, two cases are used to validate the proposed semianalytical model, the singlelinear flow case and two-well interference case. In the follow-

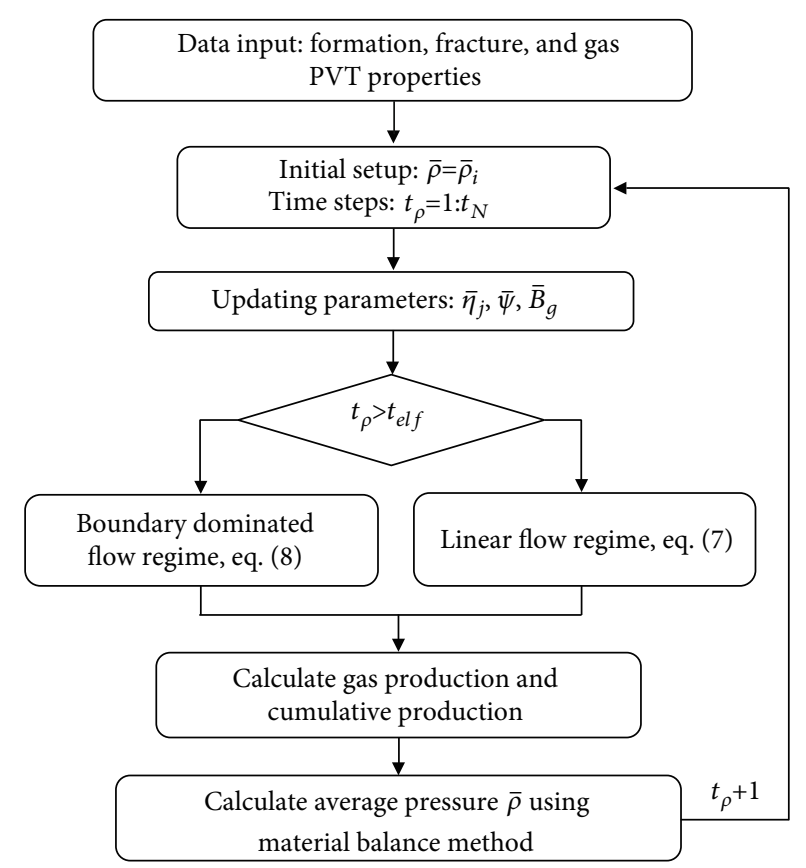

FIgURE 3: The procedure to predict the production for a singlelinear flow model.

ing, we first use the single-linear flow case shown in Figure 2(c) to validate the model in the calculation, and then, a two-well interference case shown in Figure 1(a) is used to validate the model in model assumptions. For the two cases, the reservoir and fracture properties are shown in Table 3 and the gas PVT properties are calculated using the method proposed by Lee et al. [46] and shown in Figure 4(a).

The validation result of the single-linear flow case is shown in Figure 4(b). We can find that the proposed semianalytical model has a good match with the numerical simulation results. In addition, for this case, there are mainly two flow regimes exhibited by the gas production curves on the $\log -\log$ plot-the formation linear flow and boundarydominated flow regimes. This shows that the computation of the semianalytical model is reliable.

We further analyzed the validity of the assumptions of the regional linear flow model in handling infill wellcaused fracture interference. In this case, the infill well is assumed to start to produce 720 days later than the parent well. Figure 5 shows the validation result, which shows that good matches are obtained for both the parent and infill wells. Figure 5(a) shows that the parent well has been in the boundary-dominated flow regime when it gets interfered by the infill well. It should be noted that the flow regimes after the infill time are composite for the parent well. The flow for the old SRV, the $x_{f 1}$ part shown in Figures 2(a) and $2(\mathrm{~b})$, is under the boundary-dominated flow regime, while the new SRV generated by the fracturing of the infill well is under a linear flow regime. Two methods can be used to analyze this combined flow regime. The first method is by history matching, which will be presented in Section 3.3. The other method is by straight line analysis after processing the production data by deducting the contribution from the 
TABLE 2: The composition of the typical sections shown in Figure 1.

\begin{tabular}{lrr}
\hline Typical region & Composition & Production time \\
\hline A & Linear (Figure 2(c) )+two - region linear (Figure 2(a)) & At a different time \\
B & Linear (Figure 2(c) )+convergence linear (Figure 2(b)) & At a different time \\
C & Linear (Figure 2(c) )+two - region linear (Figure 2(a)) & At the same time \\
D & Linear (Figure 2(c) )+convergence linear (Figure 2(b)) & At the same time \\
E & Two-region linear (Figure 2(a) )+two - region linear (Figure 2(a)) & At a different time \\
F & Convergence linear (Figure 2(b) )+convergence linear (Figure 2(b)) & At a different time \\
G & Two-region linear (Figure 2(a) )+convergence linear (Figure 2(b)) & At a different time \\
\hline
\end{tabular}

TABle 3: Parameters for the validation case.

\begin{tabular}{|c|c|c|c|}
\hline Parameter & Value & Parameter & Value \\
\hline Initial pressure $(\mathrm{MPa})$ & 75 & Formation temperature $(\mathrm{K})$ & 408 \\
\hline Initial water saturation (irreducible) & 0.56 & Formation thickness (m) & 25 \\
\hline Matrix permeability $(\mathrm{mD})$ & $1 \times 10^{-5}$ & Porosity of the matrix & 0.051 \\
\hline Rock compressibility $\left(\mathrm{MPa}^{-1}\right)$ & $8 \times 10^{-5}$ & Hydraulic fracture porosity & 0.3 \\
\hline Hydraulic fracture width $(\mathrm{m})$ & 0.01 & Bottom hole pressure $(\mathrm{MPa})$ & 5 \\
\hline Hydraulic fracture permeability $(\mathrm{mD})$ & 10000 & Fracture half-length of the infill well (m) & 82.5 \\
\hline Fracture half-length of the parent well (m) & 122.5 & Number of fractures for the infill well & 11 \\
\hline Number of fractures for the parent well & 16 & Number of connected fractures & 6 \\
\hline Permeability of the region between the two wells $(\mathrm{mD})$ & $3 \times 10^{-5}$ & Well space $(\mathrm{m})$ & 300 \\
\hline Permeability of the SRV for the parent well (mD) & $1 \times 10^{-4}$ & Permeability of the SRV for the infill well (mD) & $6 \times 10^{-5}$ \\
\hline
\end{tabular}

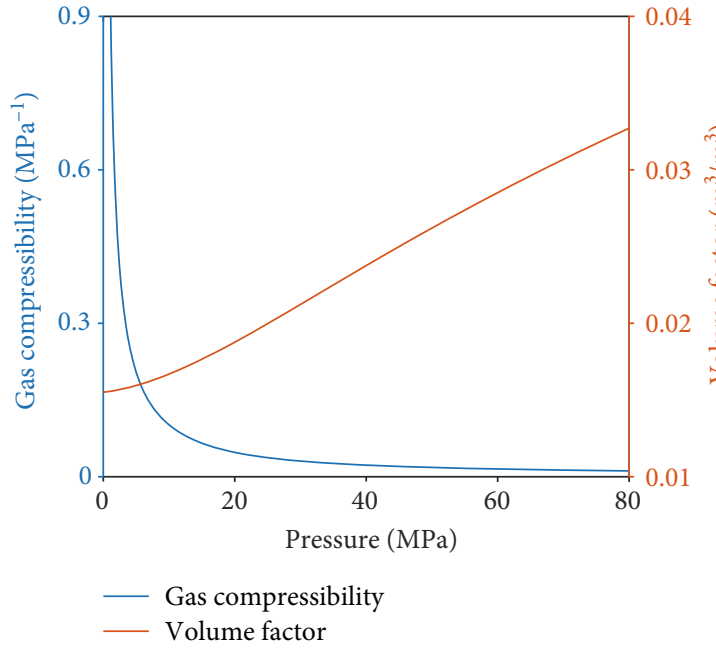

(a) Gas PVT properties

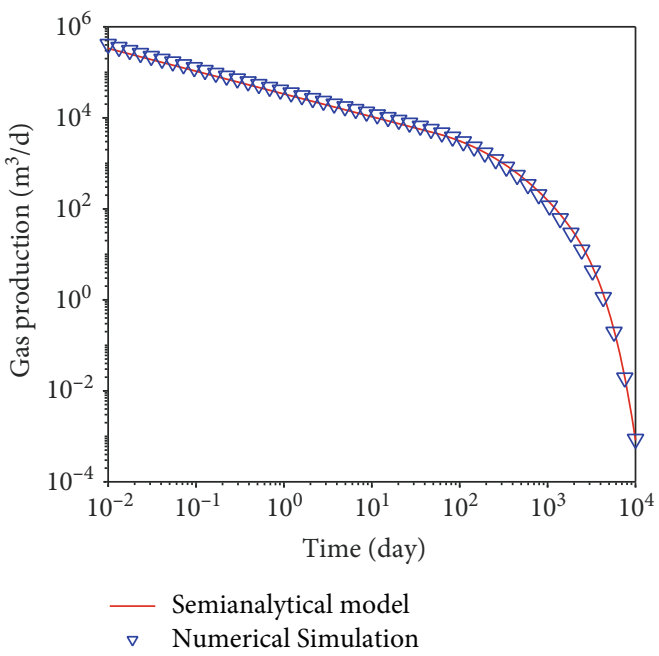

(b) Validation results for the single-linear flow

FIGURE 4: The procedure to predict the production for a single-linear flow model.

near-well SRV, but this will be our future work. One should also notice that the time shown in Figure 5(b) is the production time of the infill well, which is 720 days later than the production time of the parent well. The flow regimes cannot be exhibited by the log-log plots if the production time of the parent well is used, just like the late flow regimes shown in Figure 5(a).
3.2. Synthetic Case Study. In this section, we will analyze the infill well-caused well interference on the production performance of both the parent and infill wells. The analyzed parameters include the numbers of the connected fractures between the parent and infill wells, the length of the unconnected fractures for the infill well, the fracture numbers of the infill well, the permeability of the new SRV region 


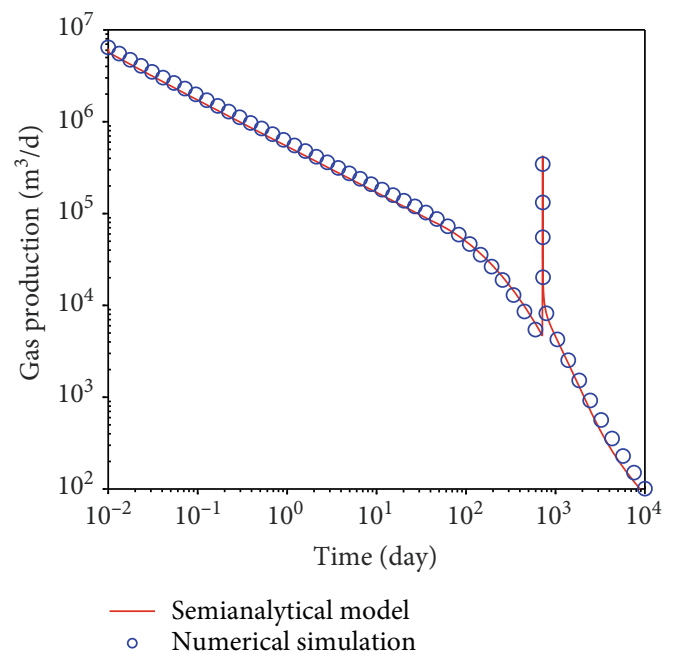

(a) Results for the parent well

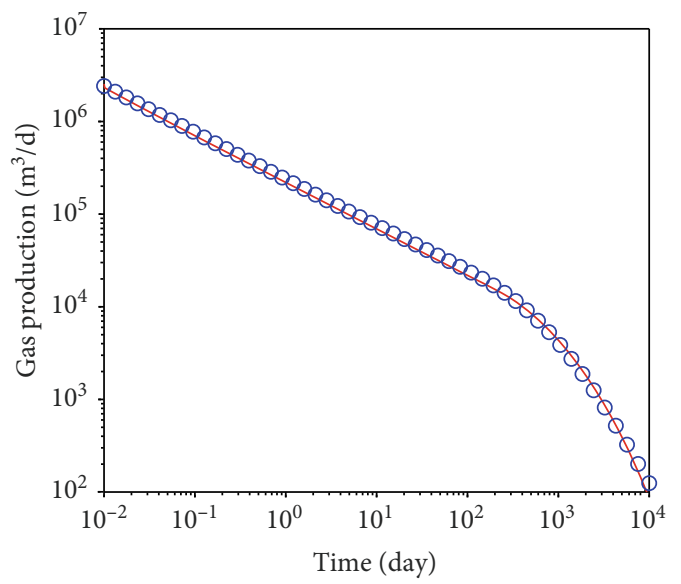

(b) Results for the infill well

Figure 5: The gas production comparison results for the two-well interference case.

TABLE 4: The analyzed parameters for the synthetic cases.

\begin{tabular}{lccc}
\hline Parameter & Value & Parameter & Value \\
\hline Fracture half-length of the parent well $(\mathrm{m})$ & 120 & Number of fractures for the parent well & 40 \\
Permeability of the near-well SRV $(\mathrm{mD})$ & $1 \times 10^{-4}$ & Infill time (day) & $360 / 540 / \mathbf{7 2 0} / 900$ \\
Number of connected fractures & $10 / \mathbf{2 0 / 3 0 / 4 0}$ & Number of fractures for the infill well & $20 / 30 / \mathbf{4 0} / 50$ \\
Permeability of the distant well SRV $\left(\times 10^{-5} \mathrm{mD}\right)$ & $1, \mathbf{3}, \mathbf{6}, 10$ & Fracture half-length of the infill well $(\mathrm{m})$ & $40 / 80 / \mathbf{1 2 0} / 160$ \\
\hline
\end{tabular}

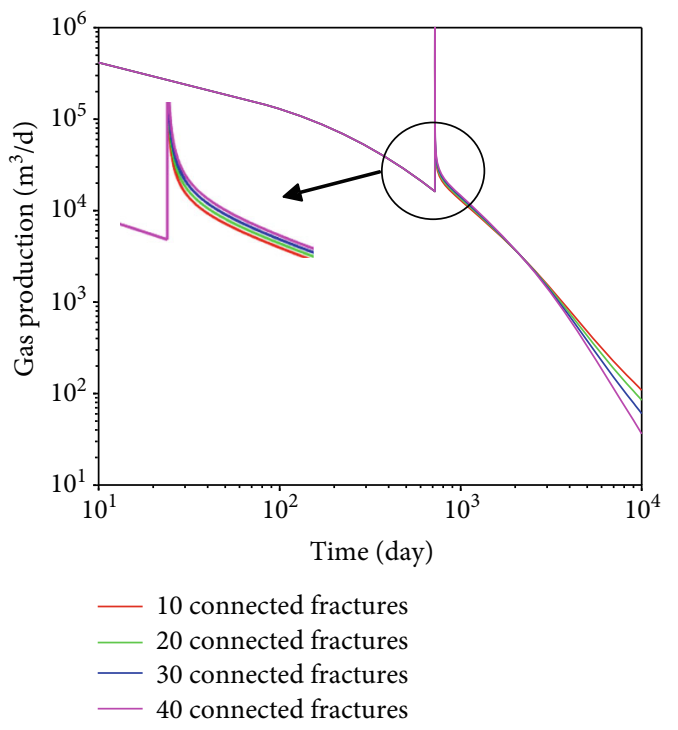

(a) Results for the parent well

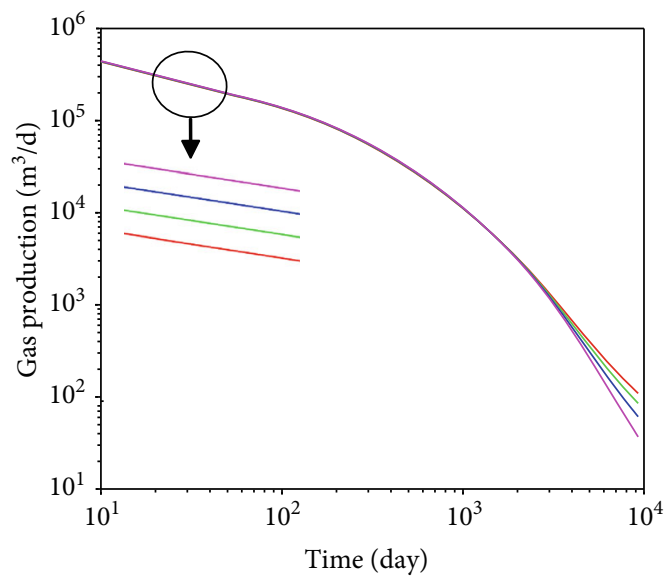

(b) Results for the infill well

Figure 6: The effects of connected fracture numbers on the gas production of both parent and infill wells.

between the parent and infill wells, and the well infill time. In this section, the fracture and SRV properties of the parent well are assumed to be the same for all the studied cases. Table 4 shows the analyzed parameters, and other parameters are shown in Table 3 . One should note that the values in bold font in Table 4 are the default value for the parameters.
3.2.1. The Effect of the Connected Fracture Numbers. Figure 6 shows the effects of connected fracture numbers on the production of the parent and infill wells. The results show that the production of the parent well will be significantly enhanced when it gets fracture interference from the infill well. This is because of the gas contribution from the far well SRV, which is generated after the hydraulic fracturing of the 


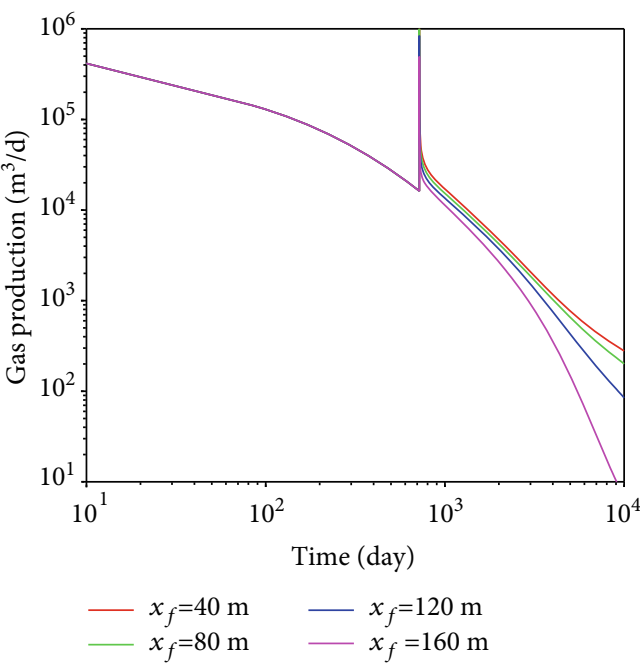

(a) Results for the parent well

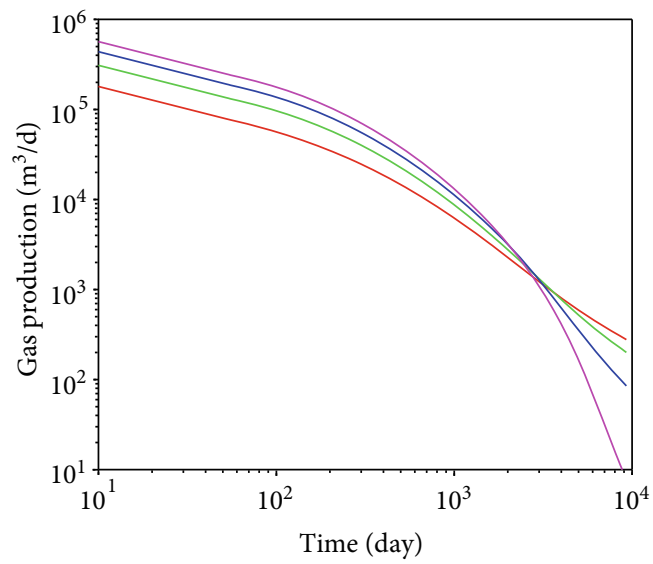

(b) Results for the infill well

Figure 7: The effects of the unconnected fracture length on the gas production of both parent and infill wells.

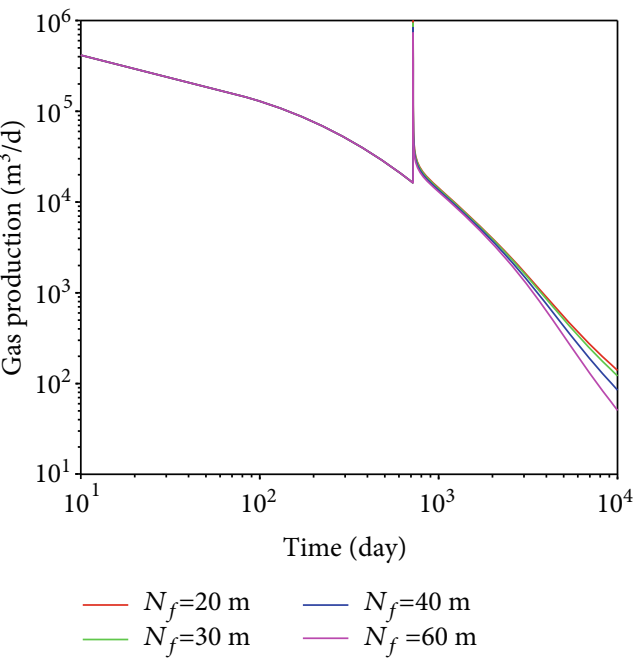

(a) Results for the parent well

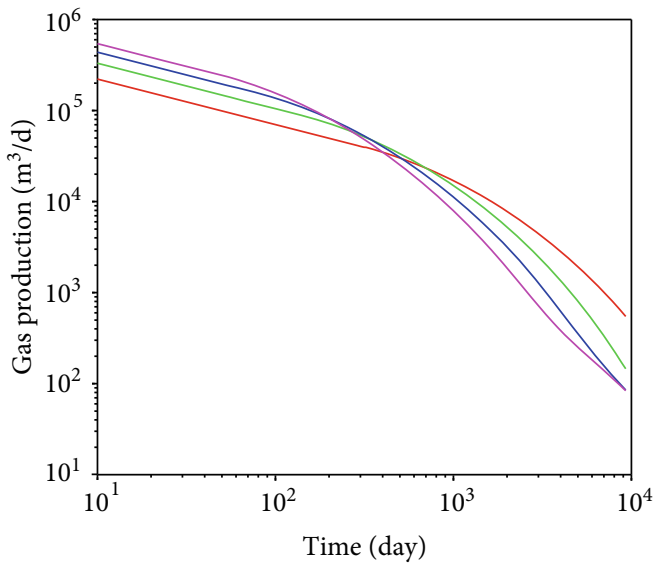

(b) Results for the infill well

FIGURE 8: The effects of fracture stages/clusters on the gas production of both parent and infill wells.

infill well. The results also show that the production of both parent and infill wells will be higher with more connected fractures at early flow regimes, while lower production rates are observed for late flow regimes. This shows that the remaining gas in the formation will be extracted by the wells earlier with more connected fractures.

3.2.2. The Effect of the Length of Unconnected Fractures. In this case, the length of the parent well is given a constant value and the length of the unconnected fractures for the infill well is given as $40,80,120$, and $160 \mathrm{~m}$ to analyze the effects of well interference.

As shown in Figure 7, the length of the unconnected fractures has a significant influence on the production of both the parent and infill wells. For the infill well, much larger SRV and control volume can be obtained with longer fracture, so the production of the infill well is significantly enhanced.
For the parent well, fracture connection can increase the gas production for all the cases but higher production will be obtained with shorter unconnected fractures. This is because a longer fracture of the infill well will increase the near SRV of the infill well and reduce the distant well SRV, which causes the production increase for the parent well.

3.2.3. The Effect of the Fracture Stages/Clusters. Figure 8 shows the effects of the fracture stages/clusters of the infill well on shale gas production. The results show that the fracture stages of the infill well have limited influence on the production of the parent well. This is because the connected fracture number is given as 20 for all the scenarios, while this may be not true in the field. Because it is more possible to have more fractures connected with the parent well if more stages/clusters are used in the hydraulic fracturing of the infill well. For the infill well, more fracture stages/clusters 


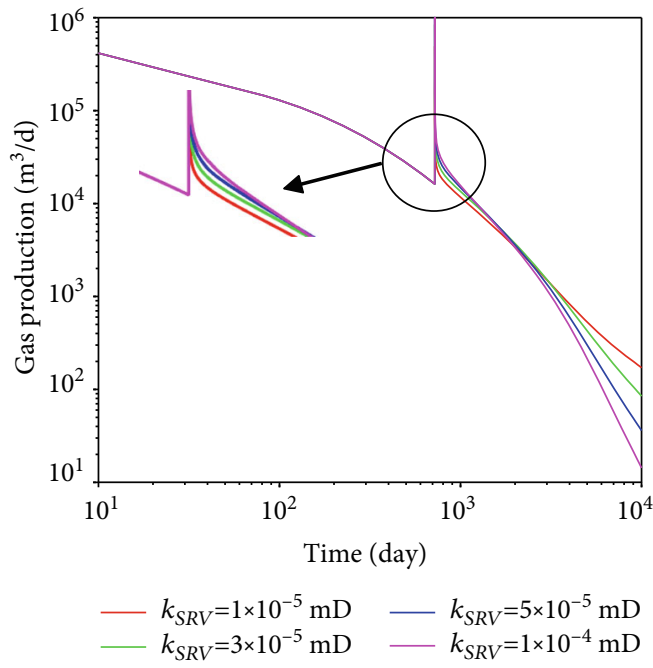

(a) Results for the parent well

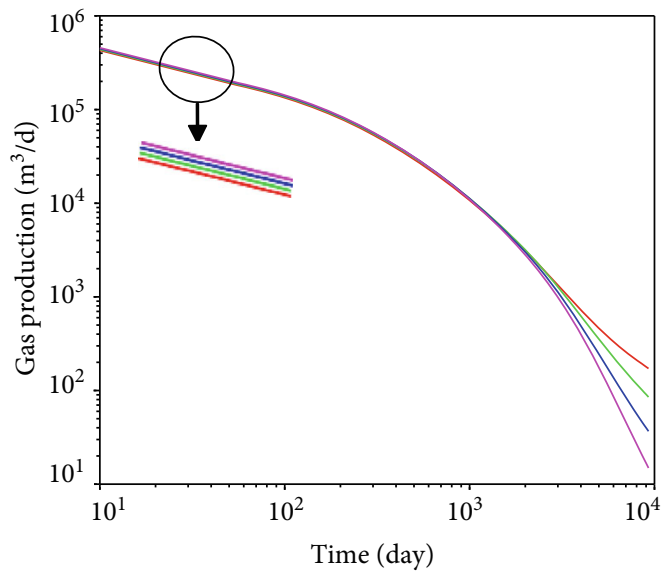

(b) Results for the infill well

FIGURE 9: The effects of the SRV permeability on the gas production of both parent and infill wells.

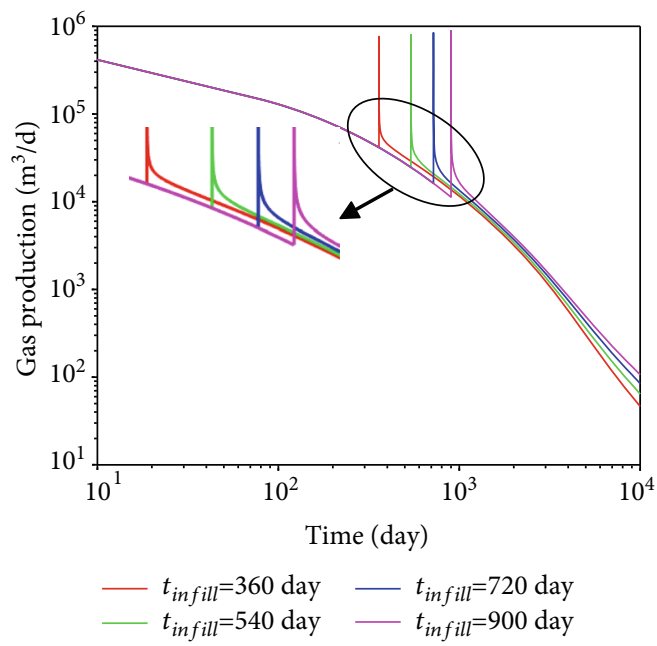

(a) Results for the parent well

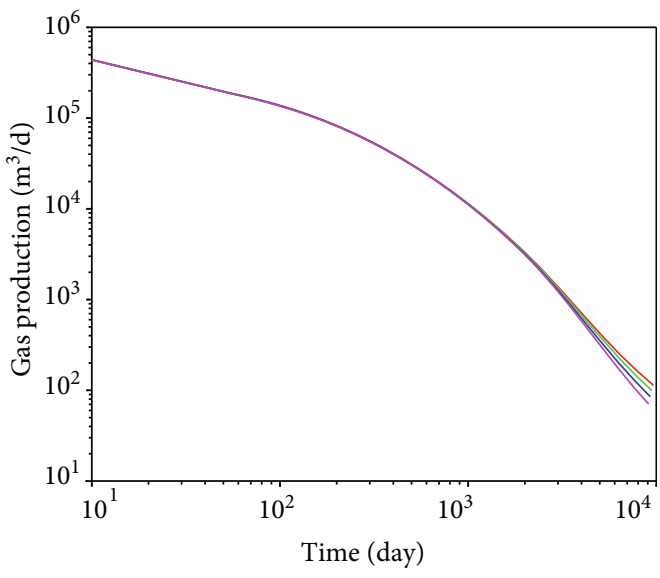

(b) Results for the infill well

FIgURE 10: The effects of the well infill time on the gas production of both parent and infill wells.

will result in higher gas production in the early flow regimes and lower in the late flow regimes. This is quite like the influence of the fracture length shown in Figure 7(b), but the influence of the fracture length is more significant with the studied parameters.

3.2.4. The Effect of the SRV Permeability. In this section, we are focused on analyzing the effects of the permeability of the distant well SRV generated during the stimulation of the infill well. For comparison, the permeability of the near well SRV for both the parent and infill wells is given as 1 $\times 10^{-4} \mathrm{mD}$. Figure 9 shows that the influence of the SRV permeability on the parent and infill well is quite similar. In the early flow regimes, larger production rates are obtained with higher SRV permeabilities, while an opposite influence is observed on the curves for the late flow regimes.
This is because more gas reserves are produced from the wells with higher SRV permeabilities and left limited remain reserves for the late flow regimes.

3.2.5. The Effect of the Well Infill Time. In this section, we assume that the infill well starts to fracture and produce at $360,540,720$, and 900 days after the parent well.

Figure 10(a) shows that well interference in later flow regimes will result in higher production "pick" when the parent well gets interfered by the infill well. In addition, the amount of production increase will be larger with later fracture interference. This is because the depletion in the control volume of the parent well is more severe and a larger proportion of the distant well SRV will contribute to the parent well. Therefore, in Figure 10(b), we can find that the production of the infill well will be lower when the infill well is added into the well pad at a later time. 


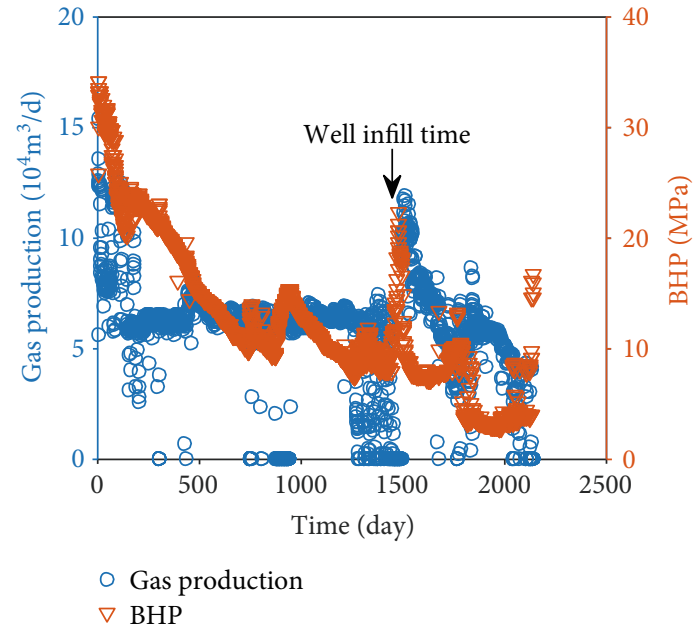

(a) Performance of the parent well

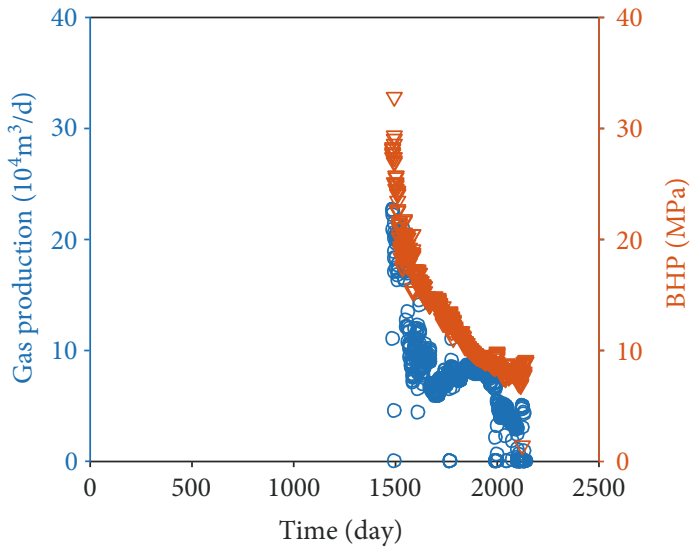

(b) Performance of the infill well

FIGURE 11: The production performance of the parent and infill wells for the field case.

TABLE 5: The formation properties and fitted parameters using the semianalytical model.

\begin{tabular}{|c|c|c|c|}
\hline Parameter & Value & Parameter & Value \\
\hline Initial pressure $(\mathrm{MPa})$ & 75 & Formation temperature $(\mathrm{K})$ & 408 \\
\hline Initial water saturation (irreducible) & 0.56 & Formation thickness (m) & 25 \\
\hline Matrix permeability $(\mathrm{mD})$ & $1 \times 10^{-5}$ & Porosity of the matrix & 0.051 \\
\hline Rock compressibility $\left(\mathrm{MPa}^{-1}\right)$ & $8 \times 10^{-5}$ & Hydraulic fracture porosity & 0.3 \\
\hline Well space $(\mathrm{m})$ & 300 & Permeability of the distant well SRV (mD) & $5 \times 10^{-5}$ \\
\hline Langmuir pressure $(\mathrm{MPa})$ & 5 & Langmuir volume $\left(\mathrm{m}^{3} / \mathrm{t}\right)$ & 3 \\
\hline${ }^{*}$ Hydraulic fracture conductivity $(\mathrm{D} \cdot \mathrm{cm})$ & 0.05 & ${ }^{*}$ Number of connected fractures & 15 \\
\hline *Number of fractures for the parent well & 15 & ${ }^{*}$ Number of fractures for the infill well & 25 \\
\hline${ }^{*}$ Half-length of the fractures for the parent well $(\mathrm{m})$ & 140 & ${ }^{*}$ Half-length of the fractures for the infill well $(\mathrm{m})$ & 90 \\
\hline *Permeability of the near-well SRV $(\mathrm{mD})$ & $5 \times 10^{-4}$ & ${ }^{*}$ Contribution ratio to the parent well & 0.7 \\
\hline
\end{tabular}

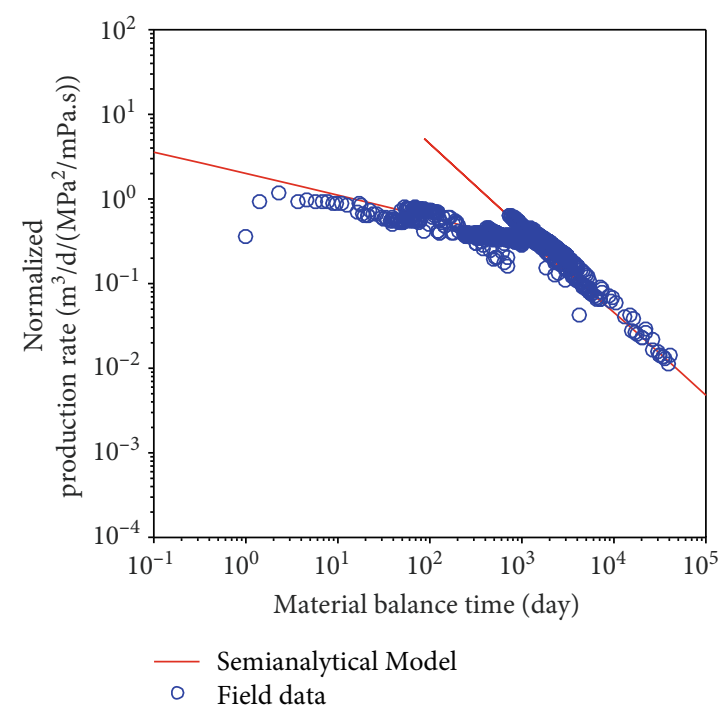

(a) Results for the parent well

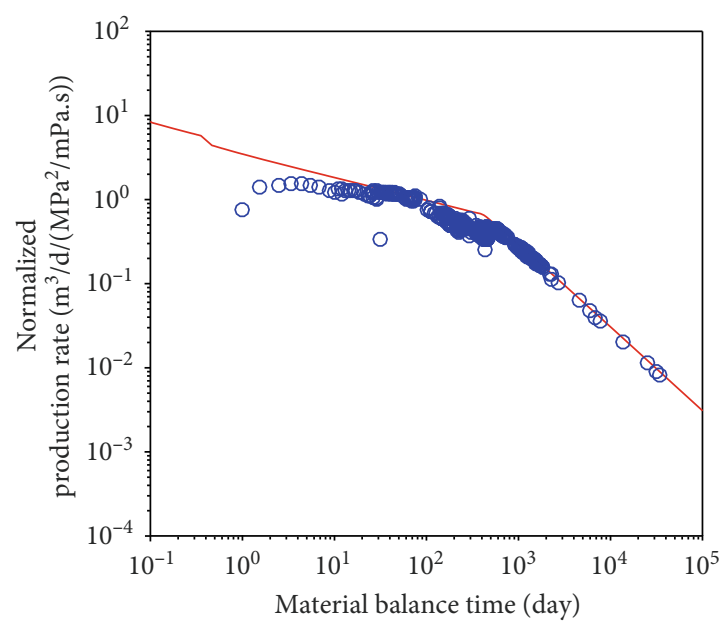

(b) Results for the infill well

FIgURE 12: The production analysis results for the parent and infill wells. 
3.3. Field Case Study. To further benchmark the proposed semianalytical model, a field case from Southwestern China is used in the analysis. The parent well is 1450 meters long and hydraulically fractured with 15 stages. After producing for 1484 days, an infill well is fractured and starts to produce. The distance between the parent and infill wells is 300 meters. Figure 11 shows the production performance of both the parent and infill wells. Significantly, there is a boom in the gas production for the parent well when the infill well is added to the well pad. Therefore, in this case, we will use the proposed semianalytical model to analyze the production data and inverse the fracture properties and evaluate the inter-well connectivity by using history matching. Some of the formation properties are shown in Table 5 .

Because the production data is under variable BHP and rate conditions, we should use the normalized production rate and material balance time to process the production data. The production data obtained using the proposed semianalytical model is also handled using this concept because of the nonlinearity of the semianalytical model. In this paper, both the production data and the semianalytical results are handled in this way. The history matching results are shown in Figure 12. For both the parent and infill wells, there are mainly two flow regimes exhibited in the log-log plots. The first flow regime is a bilinear flow regime, which is characterized by a $1 / 4$ slope on the log-log plots. The second flow regime is a boundary-dominated flow regime, which has a slope of 1 . Therefore, the approximated expressions, equations (8) and (12), are used in the semianalytical model. The history matching results show that a good match to the field data is obtained. The fitted parameters are shown in Table 5, in which character "*” is used to mark the fitted parameters. We should admit that this may be not the only one to match the field data because of the uncertainties in the model. It should be noted that the dimensionless fracture conductivity is about $2 \pi$, so the early flow regime is bilinear flow. This is following the assumption for using the bilinear flow model. One should also note that the contribution ratio to the parent well, shown in Table 5, is obtained by history matching for field cases.

\section{Conclusions}

In this paper, a practical semianalytical model is proposed to analyze the infill well-caused fracture interference on the gas production performance. Based on the studies in this paper, the following conclusions are guaranteed:

(1) Strict analytical models cannot handle the problem of infill well-caused fracture interference because the parent and infill wells are not in production at the same time, which makes the analytical model nonlinear and nonhomogeneous. The validation over the numerical simulator shows that this problem can be handled by dividing the whole model into several linear flow regions and the production of the wellbore can be obtained by adding the production contribution from all the parts
(2) When two wells are connected with high-conductivity fractures, the production of the parent well will significantly increase when the parent well gets interfered. The production rates of the wells are influenced by the fracture parameters, including the numbers of connected fractures, the length of the unconnected fractures, and fracturing stages/clusters for the infill well. Although similar effects are observed on the production rates curves, the length of the fractures and fracturing stages/clusters are particularly significant

(3) The production is also affected by the SRV permeability and well infill time, which influence the production contribution from the distant well SRV by changing the properties and the production contribution ratio to the parent well. The production increase of the parent well upon getting fracture interference will be more significant in late time infill well production

(4) The normalized production rate and material balance time can be used to analyze the production data for multiwell cases with fracture connections. The interwell connection conditions and the fracture properties of the parent and infill wells can be interpreted with the proposed semianalytical model

\section{Nomenclature}

$B$ : $\quad$ Fluid volume factor, $\mathrm{m}^{3} / \mathrm{m}^{3}$

$c_{t}$ : Total compressibility, $\mathrm{MPa}^{-1}$

$f_{\text {app: }}$ : Permeability modifer, dimensionless

$G_{p}$ : Cumulative gas production, $\mathrm{m}^{3}$

$H$ : $\quad$ Formation thickness, $m$

$k$ : Permeability, $\mathrm{mD}$

$k_{f}$ : Permeability of the hydraulic fracture, $\mathrm{mD}$

$k_{r}$ : Reference permeability, $\mathrm{mD}$

$L_{r}: \quad$ Reference length, $\mathrm{mD}$

p: $\quad$ Pressure, $\mathrm{MPa}$

$p_{i}: \quad$ Initial pressure, $\mathrm{MPa}$

$p_{L}$ : Langmuir pressure, $\mathrm{MPa}$

$p_{\text {wf }}:$ Flowing pressure, $\mathrm{MPa}$

$q_{s c}$ : Flow rate at the surface condition, $\mathrm{m}^{3} / \mathrm{d}$

$S_{g}:$ Gas saturation

$s: \quad$ Laplace constant

$s_{c}$ : Skin factor caused by the choking effect

$t$ : Time, day

$t_{p}:$ Time step

$T: \quad$ Temperature, $\mathrm{K}$

$V_{\text {inv }}$ : Investigation volume, $\mathrm{m}^{3}$

$V_{L}$ : Langmuir volume, $\mathrm{m}^{3} / \mathrm{m}^{3}$

$w_{f}$ : Fracture aperture, $\mathrm{m}^{3} / \mathrm{m}^{3}$

$x: \quad x$ direction, $\mathrm{m}$

$x_{f}$ : Half-length of hydraulic fractures, $\mathrm{m}$

$y: \quad y$ direction, $\mathrm{m}$

$y_{f}$ : Half-length of fracture space, $\mathrm{m}$.

Greeks symbols

$\Psi$ : Pseudopressure of gas $\mathrm{MPa}^{2} / \mathrm{mPa} \cdot \mathrm{s}$ 
$\eta_{r}:$ Reference diffusivity, $\mathrm{mD} \cdot \mathrm{MPa} / \mathrm{mPa} \cdot \mathrm{s}$

$\eta$ : Diffusivity, $\mathrm{mD} \cdot \mathrm{MPa} / \mathrm{mPa} \cdot \mathrm{s}$

$\Phi$ : Porosity, $\mathrm{m}^{3} / \mathrm{m}^{3}$

$\mu$ : Fluid viscosity, $\mathrm{mPa} \cdot \mathrm{s}$

$\omega$ : Coefficient.

Superscripts

-: Laplace transform.

\section{Subscripts}

D: Dimensionless

$f$ : Hydraulic fracture

$i$ : Initial condition

elf: End of linear flow

sc: At standard surface condition

$r$ : Reference variable

inv: Investigation area

wf: Flowing variable of the wellbore.

\section{Data Availability}

The data used to support the findings of this study are included in the article.

\section{Conflicts of Interest}

The authors declare that they have no conflicts of interest.

\section{Acknowledgments}

The authors acknowledge that this study was partially supported by the Fundamental Research Funds for the Central Universities (2021QN1005) and the Natural Science Foundation of Jiangsu Province (BK20210520).

\section{References}

[1] C. L. Cipolla, E. P. Lolon, J. C. Erdle, and B. Rubin, "Reservoir modeling in shale-gas reservoirs," SPE Reservoir Evaluation \& Engineering, vol. 13, no. 4, pp. 638-653, 2010.

[2] L. Huang, W. Zhou, H. Xu, L. Wang, J. Zou, and Q. Zhou, "Dynamic fluid states in organic-inorganic nanocomposite: implications for shale gas recovery and $\mathrm{CO}_{2}$ sequestration," Chemical Engineering Journal, vol. 411, article 128423, 2021.

[3] X. Zhou, Q. Yuan, Y. Zhang, H. Wang, F. Zeng, and L. Zhang, "Performance evaluation of $\mathrm{CO}_{2}$ flooding process in tight oil reservoir via experimental and numerical simulation studies," Fuel, vol. 236, pp. 730-746, 2019.

[4] X. Zhou, Q. Yuan, and X. Peng, "A critical review of the $\mathrm{CO}_{2}$ huff 'n' puff process for enhanced heavy oil recovery," Fuel, vol. 215, pp. 813-824, 2018.

[5] R. Safari, R. Lewis, X. Ma, U. Mutlu, and A. Ghassemi, "Fracture curving between tightly spaced horizontal wells," in Presented at the unconventional resources technology conference, San Antonio, Texas, USA, 2015.

[6] R. Malpani, S. Sinha, L. Charry, B. Sinosic, B. Clark, and K. Gakhar, "Improving hydrocarbon recovery of horizontal shale wells through refracturing," in Presented at SPE/CSUR unconventional resources conference, Calgary, Alberta, Canada, 2015.
[7] K. Wu, B. Wu, and W. Yu, "Mechanism analysis of well interference in unconventional reservoirs: insights from fracturegeometry simulation between two horizontal wells," SPE Production \& Operations, vol. 33, no. 1, pp. 12-20, 2018.

[8] J. P. Detring and G. Michael, "Using microseismicity to understand subsurface fracture systems and to optimize completions: eagle ford shale, TX," in Presented at the unconventional resources technology conference, Denver, Colorado, USA, 2014.

[9] E. A. Ejofodomi and F. Silva, "Using a calibrated 3D fracturing simulator to optimize completions of future wells in the Eagle Ford Shale," in Presented at the unconventional resources technology conference, San Antonio, Texas, USA, 2015.

[10] H. Lawal, G. Jackson, N. Abolo, and C. Flores, “A novel approach to modeling and forecasting frac hits in shale gas wells," in Presented at EAGE Annual Conference \& Exhibition, London, United Kingdom, 2013.

[11] B. Kurtoglu and A. Salman, "How to utilize hydraulic fracture interference to improve unconventional development," in Presented at international petroleum exhibition and conference, Abu Dhabi, UAE, 2015.

[12] A. Ataei, E. Motaei, M. E. Yazdi, R. Masoudi, and A. Bashir, "Rate transient analysis RTA and its application for well connectivity analysis: an integrated production driven reservoir characterization and a case study," in Prepared at the SPE Asia Pacific oil \& gas Conference and exhibition, Brisbane, Australia, 2018.

[13] H. Hoteit and A. Firoozabadi, "Multicomponent fluid flow by discontinuous Galerkin and mixed methods in unfractured and fractured media," Water Resources Research, vol. 41, no. 11, pp. 274-282, 2005.

[14] L. Li and S. H. Lee, "Efficient field-scale simulation of black oil in a naturally fractured reservoir through discrete fracture networks and homogenized media," SPE Reservoir Evaluation \& Engineering, vol. 11, no. 4, pp. 750-758, 2008.

[15] A. Moinfar, A. Varavei, K. Sepehrnoori, and R. T. Johns, "Development of an efficient embedded discrete fracture model for 3D compositional reservoir simulation in fractured reservoirs,” SPE Journal, vol. 19, no. 2, pp. 289-303, 2014.

[16] X. Rao, L. Cheng, R. Cao et al., "An efficient three-dimensional embedded discrete fracture model for production simulation of multi-stage fractured horizontal well," Engineering Analysis with Boundary Elements, vol. 106, pp. 473-492, 2019.

[17] H. Liu, X. Rao, and H. Xiong, "Evaluation of $\mathrm{CO}_{2}$ sequestration capacity in complex- boundary-shape shale gas reservoirs using projection-based embedded discrete fracture model (pEDFM)," Fuel, vol. 277, article 118201, 2020.

[18] X. Rao, L. Xin, Y. He et al., "Numerical simulation of twophase heat and mass transfer in fractured reservoirs based on projection-based embedded discrete fracture model (pEDFM)," Journal of Petroleum Science and Engineering, vol. 208, article 109323, 2022.

[19] Y. Wu, L. Cheng, J. Killough et al., "Integrated characterization of the fracture network in fractured shale gas reservoirs-stochastic fracture modeling, simulation and assisted history matching," Journal of Petroleum Science and Engineering, vol. 205, article 108886, 2021.

[20] Y. Wu, L. Cheng, S. Fang, S. Huang, and P. Jia, “A green element method-based discrete fracture model for simulation of the transient flow in heterogeneous fractured porous media," Advances in Water Resources, vol. 136, article 103489, 2020. 
[21] Y. Wu, L. Cheng, S. Fang, K. John, S. Huang, and P. Jia, “A novel edge-based green element method for simulating fluid flow in unconventional reservoirs with discrete fractures," SPE Journal, vol. 25, no. 2, pp. 842-866, 2020.

[22] C. Xiao, Y. Dai, L. Tian et al., "A semianalytical methodology for pressure-transient analysis of multiwell-pad-production scheme in shale gas reservoirs, part 1: new insights into flow regimes and multiwell interference," SPE Journal, vol. 23, no. 3, pp. 885-905, 2018.

[23] W. Yu, Y. Xu, R. Weijermars, K. Wu, and K. Sepehrnoori, “A numerical model for simulating pressure response of well interference and well performance in tight oil reservoirs with complex-fracture geometries using the fast embedded-discrete-fracture-model method," SPE Reservoir Evaluation \& Engineering, vol. 21, no. 2, pp. 489-502, 2018.

[24] H. Tang, B. Yan, Z. Chai, L. Zuo, J. Killough, and Z. Sun, “Analyzing the well-interference phenomenon in the Eagle Ford Shale/Austin chalk production system with a comprehensive compositional reservoir model," SPE Reservoir Evaluation \& Engineering, vol. 22, no. 3, pp. 827-841, 2019.

[25] Y. He, S. Cheng, J. Qin et al., "Interference testing model of multiply fractured horizontal well with multiple injection wells," Journal of Petroleum Science and Engineering, vol. 176, pp. 1106-1120, 2019.

[26] H. A. Al-Ahmadi and R. A. Wattenbarger, "Triple-porosity models: one further step towards capturing fractured reservoirs heterogeneity," in Presented at the SPE/DGS Saudi Arabia section technical symposium and exhibition, Al-Khobar, Saudi Arabia, 2011.

[27] M. L. Brown, E. Ozkan, R. S. Raghavan, and H. Kazemi, "Practical solutions for pressure-transient responses of fractured horizontal Wells in unconventional shale reservoirs," SPE Reservoir Evaluation \& Engineering, vol. 14, no. 6, pp. 663-676, 2011.

[28] K. Stalgorova and L. Mattar, "Analytical model for unconventional multifractured composite systems," SPE Reservoir Evaluation \& Engineering, vol. 16, no. 3, pp. 246-256, 2013.

[29] Y. Wu, L. Cheng, L. Ma et al., "A transient two-phase flow model for production prediction of tight gas wells with fracturing fluid-induced formation damage," Journal of Petroleum Science and Engineering, vol. 199, article 108351, 2021.

[30] Y. Wu, L. Cheng, S. Huang et al., “An approximate semianalytical method for two-phase flow analysis of liquid- rich shale gas and tight light-oil wells," Journal of Petroleum Science \& Engineering, vol. 176, pp. 562-572, 2019.

[31] H. Chu, X. Liao, Z. Chen, and W. J. Lee, "Rate transient analysis of a multi-horizontal-well pad with a semi-analytical method," in Prepared at the unconventional resources technology conference, Austin, Texas, USA, 2020.

[32] M. Eghbal, A. Abdolrahim, and Y. M. Ebrahim, "Production analysis PA and application of rate transient analysis RTA in carbonate oil reservoirs for reservoir characterization and connectivity," in Presented at the Offshore Technology Conference Asia, Kuala Lumpur, Malaysia, 2018.

[33] H. Yadav and S. Motealleh, "Improving quantitative analysis of frac-hits and refracs in unconventional plays using RTA," in Presented at the SPE hydraulic fracturing technology conference and exhibition, The woodlands, Texas, USA, 2017.

[34] Y. Wu, L. Cheng, S. Huang et al., "A practical method for production data analysis from multistage fractured horizontal wells in shale gas reservoirs," Fuel, vol. 186, pp. 821-829, 2016.
[35] J. Wang, L. Yu, and Q. Yuan, "Experimental study on permeability in tight porous media considering gas adsorption and slippage effect," Fuel, vol. 253, pp. 561-570, 2019.

[36] Q. Yuan, X. Zhou, J. Wang, F. Zeng, K. D. Knorr, and $\mathrm{M}$. Imran, "Control of viscous fingering and mixing in miscible displacements with time-dependent rates," AICHE Journal, vol. 65, no. 1, pp. 360-371, 2019.

[37] T. Zhang, F. Javadpour, Y. Yin, and X. Li, "Upscaling water flow in composite nanoporous shale matrix using lattice Boltzmann method," Water Resources Research, vol. 56, article e2019WR026007, 2020.

[38] Z. Sun, X. Li, W. Liu, T. Zhang, M. He, and H. Nasrabadi, "Molecular dynamics of methane flow behavior through realistic organic nanopores under geologic shale condition: pore size and kerogen types," Chemical Engineering Journal, vol. 398, article 124341, 2020.

[39] H. Xiong, D. Devegowda, and L. Huang, "EOR solvent-oil interaction in clay-hosted pores: insights from molecular dynamics simulations," Fuel, vol. 249, pp. 233-251, 2019.

[40] H. Xiong, D. Devegowda, and L. Huang, "Water bridges in clay nanopores: mechanisms of formation and impact on hydrocarbon transport," Langmuir, vol. 36, no. 3, pp. 723-733, 2020.

[41] H. Wu, D. Ma, and A. J. S. Spearing, "Fracture phenomena and mechanisms of brittle rock with different numbers of openings under uniaxial loading," Geomechanics and Engineering, vol. 25, no. 6, pp. 481-493, 2021.

[42] P. Yu, D. Dempsey, and R. Archer, "A three-dimensional coupled thermo-hydro-mechanical numerical model with partially bridging multi-stage contact fractures in horizontal-well enhanced geothermal system," International Journal of Rock Mechanics and Mining Sciences, vol. 143, article 104787, 2021.

[43] Y. Wu, L. Cheng, S. Huang, S. Fang, P. Jia, and X. Rao, “An analytical model for analyzing the impact of fracturing fluidinduced formation damage on rate transient behavior in tight formations," Journal of Petroleum Science and Engineering, vol. 179, pp. 513-525, 2019.

[44] H. Stehfest, "Algorithm 368: numerical inversion of Laplace transforms [D5]," Communications of the ACM, vol. 13, no. 1, pp. 47-49, 1970.

[45] R. A. Wattenbarger, A. H. El-Banbi, M. E. Villegas, and J. B. Maggard, "Production analysis of linear flow into fractured tight gas wells," in Presented at the SPE Rocky Mountain regional/low-permeability reservoirs symposium, Denver, Colorado, USA, 1998.

[46] A. L. Lee, M. H. Gonzalez, and B. E. Eakin, "The viscosity of natural gases," Journal of Petroleum Technology, vol. 18, no. 8, pp. 997-1000, 1966. 